\title{
THE ENVIRONMENTAL IMPACT OF ADVANCED \\ MANUFACTURING TECHNOLOGIES: \\ EXAMPLES FROM HUNGARY
}

\section{Szalavetz, A.}

The purpose of the paper is to demonstrate the beneficial impact of advanced manufacturing technologies (AMT) on firms' environmental performance. Drawing on interviews conducted with 16 Hungarian manufacturing subsidiaries on their experience with AMT, we find three functional areas, where industry 4.0 solutions can not only enhance operational excellence and cost-efficiency, but they can also improve eco-efficiency, but they can also improve eco-efficiency, namely in the field of quality management (through smart production control, data analytics and predictive modelling solutions); process optimization (through capacity planning and production scheduling solutions); and product and process engineering (through advanced virtual technologies). We also find that AMT adoption facilitated subsidiary upgrading along various dimensions. The main managerial implication is that subsidiaries need to be proactive, and emphasize also the benefits stemming from energy and resource efficiency improvement when lobbying for investment in AMT. Keywords: industry 4.0; greening, manufacturing subsidiaries; process upgrading; Hungary JEL classification: O33, O14, Q55, F23

\section{Introduction}

Ever since Porter and Van der Linde's (1995) seminal study on greening as a source of competitive advantage, firms' environmental sustainability strategies have been gaining increasing attention in the strategic management literature. Firms' strategies addressing environmental constraints and transforming them into competitive advantage have been extensively investigated: in particular, green innovation and innovation collaboration (De Marchi, 2012, Rennings, 2000), and implementation of environmental \& energy management systems (Fleiter et al., 2012).

However, the other direction of causality, the impact of firms' competitiveness enhancing actions on their environmental performance, has received less academic attention. Some aspects of this latter direction of causality are self-evident. Product innovations resulting in general improvements in product quality parameters, such as reliability and durability, can be classified as sustainability-oriented, since they extend the lifespan of the products. Process improvements that reduce waste and enhance the efficiency of energy or resources use will obviously boost not only competitiveness, but will also contribute to greening. Investment in new production equipment, replacing outdated, low-efficiency equipment, might not only increase productivity and quality, but new machinery is usually also more energy-efficient than older vintages, hence firms' unit energy consumption decreases.

This paper argues that above and beyond these trivial examples, a strong case can be made for a direction of causality running from competitiveness enhancement to improved sustainability. We explore one manifestation of this direction of causality: we demonstrate 
that manufacturing companies that adopt advanced manufacturing technologies (AMT) in order to enhance or sustain their competitiveness, will at the same time, improve their environmental performance - as a beneficial side-effect of these technologies.

We investigate the experience of a sample of Hungarian manufacturing subsidiaries that have adopted various advanced manufacturing technologies pertaining to industry 4.0. This context seems insightful also from the point of view of demonstrating the strong correlation among various dimensions of upgrading, in particular process upgrading, functional upgrading, environmental upgrading and upgrading in terms of digital readiness.

Obviously, the importance of individual AMT solutions may vary across value chain actors (lead companies, manufacturing subsidiaries). Consequently, it is indispensable to restrict the focus of our investigations. In this paper, we focus on manufacturing subsidiaries, seeking to enhance their competitiveness by reducing costs and improving their production capability.

Note that in the case of manufacturing subsidiaries, competitiveness refers to intrafirm or intra-network competition for additional mandates, resources, and for improved position and weight (Birkinshaw, 2000). Accordingly, although seemingly also highly relevant for a research topic discussing the relation between AMT adoption and greening, we do not investigate the impact of selected AMT solutions on greening if the main beneficiaries of these solutions are lead companies, i.e. value chain orchestrators, rather than manufacturing subsidiaries. Hence, we do not discuss product and business model innovations, or the impact of AMT adoption on green supply chain management. We do not discuss the example of additive manufacturing (3D printing) either, although this latter technology is regarded to have a huge potential to enhance the resource-efficiency of production, to reduce waste, to green the products themselves and to prompt the emergence of shorter, localized value chains (Bermann, 2012; Ford and Despeisse, 2016). However, in order to exploit this technological novelty or business model innovations, entrepreneurship and independent market development are required, i.e. activities that do not characterize manufacturing subsidiaries. We are concerned only with technological novelties that are expected to improve the performance indicators of production and of the support functions that are closely related to production.

This perspective is narrow enough to allow for in-depth insights on (i) causality running from competitiveness based on improved production capability, to greening; and (ii) the interconnections among dimensions of upgrading.

Our analysis draws on two research methods. First, we performed a focused survey of the literature, and brought together engineering approaches that discuss the features of industry 4.0 technologies and approaches from the management literature discussing corporate environmental sustainability. Second, we rely on insights gained from interviews carried out by the author of this paper, in the framework of two research projects on the impact of industry 4.0 technologies on manufacturing subsidiaries in Hungary (Szalavetz, 2016; Szalavetz, 2017).

The remainder of the paper is structured as follows. First, we briefly summarize the related literature. Next, we outline the research method, and introduce the sample of the companies whose experience represents the empirical evidence. We then turn to the results: present and discuss three areas, where the 'beneficial environmental side-effects' of AMT adoption become manifested. Finally, we provide some concluding remarks and highlight the managerial implications. 


\section{Theoretical Background}

Investigations focusing on the impact of AMT adoption on environmental performance can draw on two complex strands of research. The first one concerns the multidisciplinary approaches (science, engineering and management) discussing the properties and the implications of new manufacturing technologies. Papers in the second strand of research focus on corporate greening - a huge and multifaceted scholarship in itself, with multiple subfields. Two important subfields, closely related to our research, are the relation between greening and business performance and the relation between greening and innovativeness. The prominent findings of these two strands of literature are summarized below.

Recently, a bundle of new technologies penetrated into manufacturing and into production related support activities. These new enabling technologies are expected to produce unprecedented improvements in the performance indicators of production, for example, in the capacity utilization rate, in the accuracy of processing, and in other qualitative operational performance indicators, such as lead-time and flexibility. Moreover, they are expected to significantly improve adopters' cost-efficiency. At the same time, they are bound to bring about disruptive effects in the way production activities are performed, and value is created and captured. This revolutionary impact makes the new era of manufacturing be referred to as the fourth industrial revolution or industry 4.0 for short (Brettel et al., 2014; Kagermann et al., 2013).

The new era is represented by cyber-physical production systems (Monostori et al., 2016), while previous technological revolutions were driven by technologies such as the steam power (mechanization); electricity (assembly line, mass production); electronics and information and communication technology (automation). Cyber-physical production systems support manufacturing by providing real-time information about its status and by storing and processing the extracted data, which helps to identify the root causes of any problems and disruptions.

Manufacturing becomes 'smart' as a result of the application of a variety of technological novelties, including the Internet of Things, big data, artificial intelligence, cloud computing, 3D printing (additive manufacturing), collaborative industrial robots, and virtual technologies (Manyika et al., 2013).

Cyber-physical production systems with embedded computational intelligence will optimize production and enable companies to manage their products across their lifecycles. Consequently, companies will use fewer resources more efficiently (Kagermann, 2015).

One of the classical references concerning the interdependence of corporate sustainability strategy and business performance is Elkington's (1997) triple bottom line approach that argues for a balanced consideration and simultaneous management of economic, social and environmental dimensions of sustainability. In the past two decades, environmental sustainability has gradually become the cornerstone of manufacturing company strategies in advanced economies. The classical theoretical framework of the 'green imperative' is the natural-resource-based view, developed in Hart, 1995 (see also Menguc and Ozanne, 2005). Corporate greening has partly been driven by government regulation and incentives, partly by increasing customer awareness, and partly by the recognized positive relation between firms' environmental and business performance (Porter and Van der Linde, 1995; see also a comprehensive review of the literature by Albertini, 2013). 
Analyses of the relation between environmental performance and business performance commonly underscore that most manufacturing companies have a large, unexploited eco-efficiency potential (e.g. Backlund et al., 2012). Overcoming the barriers of exploiting this potential (closing the efficiency gap) represents non-negligible profit opportunity (Orsato, 2009). Closing firms' eco-efficiency gap requires innovation (e.g. Carrillo-Hermosilla et al., 2010; Rennings, 2000), in particular process innovations, both in terms of incremental improvements (cf. the literature about synergy between lean, Six Sigma and green, surveyed in Garza-Reyes, 2015) and more radical changes implying leapfrogging to best available technologies.

Drawing on the surveyed literature, and investigating the challenges and opportunities faced by manufacturing subsidiaries, we make the following propositions. Facing a continuous and intensive pressure on costs, manufacturing subsidiaries are required to improve productivity and upgrade their capabilities on a continuous basis. To do so, they keep investing, learning and accumulating capabilities to achieve operational excellence. In an industry 4.0 era, AMT adoption bears the promise of achieving these objectives. AMT adoption, however, has beneficial side-effects: it also improves adopters' environmental performance.

\section{Research Method and Sample}

As our aim is not to measure environmental performance improvement in a sample of companies and formally relate improvement to AMT adoption, but rather our purpose is to explore how competitiveness-enhancing initiatives involving AMT adoption can entail eco-efficiency improvement in manufacturing subsidiaries, the chosen research method is comparative case analysis.

We synthesize - from an environmental sustainability-oriented business and management perspective - the results of the author's past interviews on the experience of Hungarian subsidiaries with industry 4.0 technologies.

Interviews were conducted in the framework of two research projects in 2016 and 2017 with Hungarian manufacturing subsidiaries operating in the automotive $(n=6)$, electronics $(n=5)$ and machinery $(n=5)$ industries. In this paper, we rely on the experiences of altogether 16 large, foreign-owned companies (the average number of employees was 1,186 in 2015) displaying relatively high adoption of industry 4.0 technologies.

Our interviews investigated the features of AMT adopted by these firms, the motivations of technology adoption, and the impact of AMT on the given firm's performance, on the nature of work and on local capabilities. Our informants, chief executive officers or technology officers replied to open-ended questions and provided rich and multifaceted information about their experiences with AMT solutions that had been adopted to support both the core (production) function and a number of support activities. We applied inductive reasoning to derive general patterns and principles from the narratives of the managers interviewed, and explore the mechanisms by which AMT adoption improves sustainability. Inductive reasoning contributes to exploring previously researched phenomena (investments in AMT and eco-efficiency) from a new perspective: spillovers from competitiveness enhancing initiatives to eco-efficiency (cf. Glaser and Strauss, 1967 on qualitative research methods). 
The focus of our interview questions helped us control for the factors that may distort the causality of the arguments. Our questions addressed the impact of AMT adoption on subsidiary performance, on general changes in corporate practices and on the nature of work (the list of the interview questions is presented in the Appendix). We used this qualitative information to derive insights about the impact of AMT on environmental performance.

\section{Findings}

A thorough review of the rich qualitative information provided by the executives interviewed points to three main areas, where the deployment of industry 4.0 technologies has improved not only adopters' cost competitiveness and production capabilities, but also their environmental performance, namely in the field of (i) quality management (through smart production control, data analytics and predictive modelling solutions); (ii) process optimization (through capacity planning and production scheduling solutions); (iii) product and process engineering (through advanced virtual technologies).

Investigating the motivations of the surveyed companies to deploy AMT solutions, production quality (operational excellence) and process efficiency improvement proved to be the most conspicuous commonalities.

To improve production quality, smart production control and quality management solutions have been deployed. Production control refers to automated process monitoring and extraction of data about process and product parameters. These data are analyzed by computational intelligence that visualizes production status, diagnoses problems, and, based on machine learning methods, it can even make predictions, e.g. regarding maintenance needs, or regarding the disturbances that are bound to emerge. For example, tool breakage, product defects or equipment failure were signaled by the system much before they materialized. Thus, a number of disturbances could be prevented, resulting in fewer product defects and fewer occurrence of early tool degradation or tool crashes. Improvement in these key performance indicators can, however, be interpreted also in terms of greening: reduced waste and improved resource productivity.

Obviously, disturbances and defects have not been completely eliminated, but due to the process control, data acquisition and processing solutions, they were discovered much earlier than before. Traditionally, most product defects were discovered only at the end of the production process as a result of end-of-line sampling and testing procedures. Defect-related economic losses were thus much higher, and the environmental repercussions of the related waste were more serious than under AMT-supported process and quality control. Now that a previously unimaginable number of process and product parameters are measured, and automatic in-line inspection points included, contingent defects are effectively connected to the process stage where they were generated. A further benefit of the smart systems is that the destructive testing of the quality parameters of finished products has become superfluous. Consequently, the waste of resources related to the quality control procedure itself, was eliminated.

Process defects that resulted in excess energy consumption were also easier and quicker to detect. One example is the case of leaks in the compressed air system. Compressed air is a widely-used, energy-intensive utility. The smart production monitoring and control systems of the surveyed companies could detect the reduction in compressed air pressure, 
practically real-time. In this way, the problem could be addressed immediately, which contributed to a significant reduction of waste (leaks are crucial sources of wasted energy, sometimes wasting $20 \%$ of compressor's output).

The second area where industry 4.0 solutions have had beneficial environmental side-effects is process optimization. The surveyed companies invested in smart production planning and production scheduling software tools to optimize processes and eliminate bottlenecks. This resulted in reduced idle time of the production equipment. As the power consumption of $\mathrm{CNC}$ machines during idle state is almost as much as in production (Dornfeld, 2014), this outcome exemplifies the beneficial environmental side-effects (in this case, improved energy efficiency) of investments aiming to enhance operational efficiency.

Plant logistics was another major target of process efficiency improvement initiatives. Logistics planning was supported by advanced modelling and virtual technologies that allowed for the analysis of routing alternatives. This optimized material flows, eliminated unnecessary transport and material handling, and thus, contributed also to eco-efficiency.

Our informants' accounts about the way the digitalization of manufacturing contributed to process efficiency improvement can be interpreted as AMT providing digital support to companies' traditional lean initiatives - see Behrendt et al. (2017) for an argument that industry 4.0 needs to be understood as digitally enabled lean. Another, complementary interpretation is that AMT adoption contributes to the digitalization of the well-known Six Sigma tools (Define, Measure, Analyze, Improve, Control (DMAIC) - (C) Motorola). Digitalization, e.g. the automation of process control necessitated the exact definition of processes, the development of process measures and the definition of key performance indicators. Once the processes had been defined and metrics developed, purchased business analytics software could be tailored to the specific needs of the surveyed companies. A huge number of automatically measured process parameters were fed into business analytics software that processed information. These were the prerequisites of the surveyed companies' shifting to data-driven decision-making, which resulted in a spectacular improvement of overall process efficiency and, as a beneficial side-effect, in resource efficiency.

Improved environmental performance was not only a beneficial side-effect of process efficiency improvement: digital DMAIC was applied also directly in corporate environmental management. Our informants reported that energy management is usually integrated in (it is part of) the digital production management solution. Beyond facilitating compliance to regulations and to voluntary environmental standards (such as ISO 14001, ISO 50001), digital energy management solutions have also raised awareness of and supported interventions aiming at enhancing energy-efficiency. The specific DMAIC steps were as follows. Energy consumption is measured real-time and on a granular (equipment-specific) level. Consumption data are stored, real-time consumption and historical trends are visualized. Visual technologies make it easy to identify deviations, for example, peaks in energy consumption. The root causes of the deviations are easier to detect and decisions on corrective measures are substantiated by data. For example, peak consumption can be mitigated and energy consumption stabilized through changing production order or by switching off unnecessary machinery during peak periods. 
The above-reviewed impacts of AMT adoption on both process efficiency improvement and greening provide empirical evidence for the close connection between these concepts. At the same time, the reviewed mechanisms highlight the interrelation among process upgrading, environmental upgrading, functional upgrading (process development and process optimization were delegated to subsidiary-level), and upgrading in terms of digital readiness.

The third area where the beneficial impact of competitiveness enhancing AMT adoption on environmental sustainability was straightforward, is engineering (products and processes). Cyber-physical systems enable the fusion of virtual and real worlds and allow for virtual experimentation. Several companies in the sample have invested in advanced virtual engineering solutions, in order to improve their competitiveness and achieve functional upgrading. When the product mix was changed or production ramped up for the serial production of newly introduced products, subsidiary engineers were entrusted with adapting the processes and reorganizing the flow of resources. Relying on advanced virtual simulation solutions, the layout of assembly lines, work cells, or the motion of robots could be virtually designed and validated. In this way, subsidiary engineers could experiment with alternative technological solutions without wasting material and energy by producing physical try-outs for experimentation.

In a similar vein, the virtual design of product components, and the simulation of product properties (material fatigue, thermal deformation, tensile strength, solidity) have not only speeded up product development, but have also enhanced resource efficiency.

Figure 1 | A bidirectional interrelation between subsidiary competitiveness and environmental performance

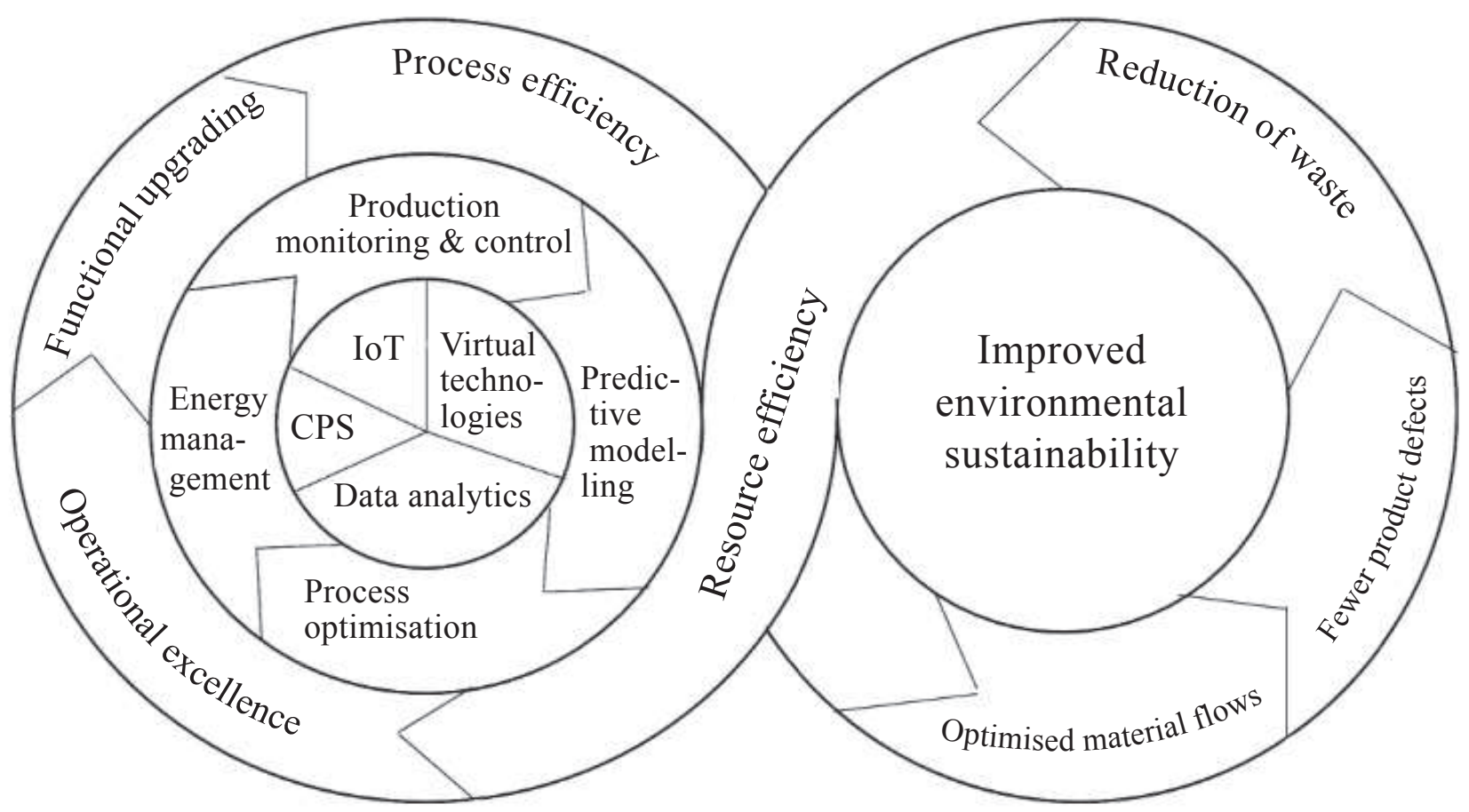

Competitiveness

Environmental performance improvement 
Altogether, subsidiary reliance on advanced virtual solutions has not only enhanced their digital upgrading (digital transformation), and has not only facilitated process and/ or product upgrading, but it has also contributed to manufacturing subsidiary engineers' taking up advanced technological activities (functional upgrading). At the same time, these technologies have contributed to environmental performance improvement.

Figure 1 summarizes the findings, and visualizes the bidirectional interrelation between digital-solutions-triggered competitiveness improvement and environmental performance improvement in manufacturing subsidiaries.

\section{Conclusions and Managerial Implications}

Based on the experience of Hungarian manufacturing subsidiaries, this paper argued that the adoption of advanced manufacturing technologies will not only improve operational excellence and increase cost effectiveness - two important factors that determine the competitiveness of manufacturing subsidiaries - but will also have a beneficial impact on the environmental performance of these companies.

We have identified three functional areas where the application of a heterogeneous set of industry 4.0 solutions produced substantial improvement in eco-efficiency, and contributed to the reduction of resource utilization: production control and quality management, process optimization and virtual product and process engineering.

We also argued that process upgrading, environmental upgrading and functional upgrading are closely interrelated. The surveyed evidence indicates that AMT adoption (digital upgrading) facilitated subsidiary upgrading along various dimensions.

Our findings have important managerial implications. Some of the implications and the related recommendations apply to all manufacturing companies, others are specific to manufacturing subsidiaries operating in countries whose growth and modernization depend on foreign direct investment inflows and on the upgrading of local manufacturing subsidiaries.

A prominent general implication is that companies should acknowledge the existence of spillovers from competitiveness enhancing AMT adoption to eco-efficiency. Accordingly, they are recommended to plan and implement effective learning mechanisms to enhance these spillovers: set environmental targets, define appropriate key performance indicators and track progress.

Regarding the managerial implications that are specific to the latter group of countries, the often-mentioned importance of local subsidiaries being proactive and entrepreneurial (Birkinshaw, 2000) applies in this case as well. As AMT adoption is expected to trigger upgrading in various fields, subsidiaries should try to be pioneer adopters instead of regarding AMT as a threat to local employment. When lobbying for investment in AMT, subsidiaries need to include also the benefits stemming from energy and resource efficiency improvement in the economic calculations that describe the return on investment. This way, they might more effectively influence corporate decision-making.

Once AMT-solutions are deployed, subsidiaries also need to lobby for performing business analytics locally, and obviously, demonstrate relevant capabilities. Subsidiaries should track and systematically communicate (both within the global organization and externally) their environmental performance improvement. Accordingly, they need to conduct initial audits (e.g. an energy audit to identify energy savings potential). 
Subsidiaries might consider positioning themselves as competence centers with respect to environmental performance improvement. This necessitates indigenous capability accumulation and own account expenses, e.g. the development of specific software applications. Since both AMT adoption and proactive environmental management open up opportunities for local innovation collaboration, which would increase the local embeddedness of the global owner, subsidiaries should strive to identify and exploit these opportunities.

\section{References}

Albertini, E. (2013). Does environmental management improve financial performance? A meta-analytical review. Organization \& Environment, 26(4), 431-457.

Backlund, S., Thollander, P., Palm, J., \& Ottosson, M. (2012). Extending the energy efficiency gap. Energy Policy, 51, 392-396.

Behrendt, A., Müller, N., Odenwälder, P., \& Schmitz, C. (2017). Industry 4.0 demystifiedlean's next level. Retrieved March 3, 2017 from http://www.mckinsey.com.

Berman, B. (2012). 3-D printing: The new industrial revolution. Business Horizons, 55(2), 155-162.

Birkinshaw, J. (2000). Entrepreneurship in the global firm. London: SAGE.

Brettel M., Friederichsen N., Keller M., \& Rosenberg M. (2014). How virtualization, decentralization and network building change the manufacturing landscape: An Industry 4.0 Perspective. International Journal of Mechanical, Aerospace, Industrial, Mechatronic and Manufacturing Engineering, 8(1), 37-44.

Carrillo-Hermosilla, J., Del Río, P., \& Könnölä, T. (2010). Diversity of eco-innovations: Reflections from selected case studies. Journal of Cleaner Production, 18(10), 1073-1083.

De Marchi, V. (2012). Environmental innovation and R\&D cooperation: Empirical evidence from Spanish manufacturing firms. Research Policy, 41(3), 614-623.

Dornfeld, D. A. (2014): Moving towards green and sustainable manufacturing. International J. of Precision Engineering and Manufacturing-Green Technology, 1(1), 63-66.

Elkington, J. (1997). Cannibals with forks: The triple bottom line of 21 st century business. Oxford: Capstone Publishing.

Fleiter, T., Hirzel, S., \& Worrell, E. (2012). The characteristics of energy-efficiency measures-a neglected dimension. Energy Policy, 51, 502-513.

Ford, S., \& Despeisse, M. (2016). Additive manufacturing and sustainability: an exploratory study of the advantages and challenges. Journal of Cleaner Production, 137, 1573-1587.

Garza-Reyes, J. A. (2015). Green lean and the need for Six Sigma. International J. of Lean Six Sigma, 6(3), 226-248.

Glaser, B. G., \& Strauss, A. L. (1967). Discovery of Grounded Theory. Mill Valley, CA: Sociology Press.

Hart, S. L. (1995). A natural-resource-based view of the firm. Academy of Management Review, 20(4), 986-1014.

Kagermann, H. (2015). Change through digitization-Value creation in the age of Industry 4.0. In: Albach, H. et al. (Eds.) Management of permanent change. Wiesbaden: Springer, pp. 23-45.

Kagermann H., Helbig J., Hellinger A., \& Wahlster W. (2013). Recommendations for Implementing the Strategic Initiative INDUSTRIE 4.0: Securing the Future of German Manufacturing Industry. Forschungsunion. Retrieved January 14, 2016 from http://www. acatech.de/. 
Manyika J., Chui M., Bughin J., Dobbs R., Bisson P., \& Marrs A. (2013). Disruptive

Technologies: Advances that will transform life, business and the global economy. New York: McKinsey Global Institute.

Menguc, B., \& Ozanne, L. K. (2005). Challenges of the "green imperative": A natural resourcebased approach to the environmental orientation-business performance relationship. Journal of Business Research, 58(4), 430-438.

Monostori, L., Kádár, B., Bauernhansl, T., Kondoh, S., Kumara, S., Reinhart, G., Sauer, O., Schuh, G, Sihn, W., \& Ueda, K. (2016). Cyber-physical systems in manufacturing. CIRP Annals-Manufacturing Technology, 65(2), 621-641.

Orsato, R. J. (2009): Sustainability strategies. When does it pay to be green? Basingstoke: Palgrave Macmillan.

Porter, M. E., \& Van der Linde, C. (1995). Toward a new conception of the environmentcompetitiveness relationship. Journal of Economic Perspectives, 9(4), 97-118.

Rennings, K. (2000). Redefining innovation-eco-innovation research and the contribution from ecological economics. Ecological Economics, 32(2), 319-332.

Szalavetz, A. (2016). Chronicle of a revolution foretold. Studies in International Economics, Special issue of Külgazdaság, 2(2), 29-51.

Szalavetz, A. (2017). Industry 4.0 and capability development in factory economies. Unpublished manuscript (available upon request).

\section{Author}

\section{Andrea Szalavetz}

Senior Research Fellow

Institute of World Economics, MTA KRTK

45, Budaörsi út, $\mathrm{H}-1112$

Budapest, Hungary

szalavetz.andrea@krtk.mta.hu

This research was supported by the National Scientific Research Fund of Hungary (K116173). 


\section{Appendix 1}

\section{Interview protocol}

General information

1. Please specify the nationality of the parent company: where is the headquarters located?

2. Please specify the main products of the company.

3. Please indicate the number of employees in 2015.

\section{Motivations of adopting advanced manufacturing technologies (AMT)*}

*AMT and industry 4.0 technologies are used interchangeably

1. What kind of 'industry 4.0' technologies / solutions have been deployed at your company, in the past half a decade?

2. What was the main motivation of investment (cost reduction, employment reduction, cost efficiency increase, productivity increase; lead time increase; better overview of the processes, more flexibility, operational excellence; environmental sustainability, etc.) Please specify the motivations in the case of each technological solution.

\section{Experience with AMT deployment}

1. Which features of the deployed solutions do you consider as the main novelty that illustrates the alleged revolutionary character of industry 4.0 ?

2. What were the main difficulties associated with technology deployment? How did your company address them?

3. Did the newly deployed technologies deliver? Did they produce the expected improvements? Please specify the impact of each newly deployed technological solution on performance.

4. In which field was the impact of the new solutions the most beneficial, and why? Please explain.

5. Were there any areas where unexpected beneficial effects have been observed?

6. Were there any activities where the impact of the new technology / solutions did not produce the expected results? What was the reason?

\section{Impact of AMT deployment on employment and the nature of work}

1. Did industry 4.0 technology deployment bring about layoffs at your company? If yes, in which functions?

2. How did overall corporate practices change as a result of the new technological solutions? Please provide detailed examples with respect to (1) production and production management; (2) logistics; (3) quality control; (4) process and product engineering; (5) maintenance; (6) administration?

3. What were the new skills required in the individual functions? 


\section{Impact of AMT deployment on upgrading}

1. Is it safe to say, that the deployment of advanced manufacturing technologies opened up opportunities for the upgrading of your company's activities? If yes, in which fields was upgrading manifested?

2. Is it safe to say that AMT deployment enhanced only operational excellence (in the broad sense)? Did it contribute also to the upgrading of the local technological capabilities / R\&D capabilities? Please provide examples. 